\title{
Belief, Re-identification and Fineness of Grain
}

\author{
Bénédicte Veillet
}

\begin{abstract}
The so-called 're-identification condition' (Kelly 2001) has played an important role in the most prominent argument for nonconceptualism, the argument from fineness of grain. A number of authors have recently argued that the condition should be modified or discarded altogether, with devastating implications for the nonconceptualist (see, e.g., Brewer 2005, Chuard 2006). The aim of this paper is to show that the situation is even more dire for nonconceptualists, for even if the re-identification condition remains in its original form, the argument from fineness of grain still fails to make the case for nonconceptualism. The paper's central case rests on two claims: according to the first, if the re-identification condition holds, then some beliefs will represent some properties nonconceptually; and according to the second, if some beliefs represent some properties nonconceptually, the argument from fineness of grain fails to make the case for nonconceptualism in any relevant sense. It follows that if the re-identification condition holds, the argument from fineness of grain fails to make the case for nonconceptualism.
\end{abstract}

The so-called 're-identification condition' (Kelly 2001) has played an important role in the most prominent argument for nonconceptualism, the argument from fineness of grain. ${ }^{1}$ Very roughly, the condition states that in order for a subject $S$ to represent a property conceptually, $\mathrm{S}$ must have the ability to re-identify instances of that property at different times. ${ }^{2}$ The argument from fineness of grain proceeds to point out that perceptual experience often represents very fine-grained, determinate properties - the particular green shade of a cactus, or its determinate irregular shape-and that subjects are generally unable to re-identify these properties in the ways specified by the re-identification condition. Experience must therefore represent these fine-grained, determinate properties nonconceptually.

A number of authors have recently expressed worries about the strength and scope of the re-identification condition and have argued that it should be modified or dispensed with altogether. This has unfortunate implications for the nonconceptualist, since the argument from fineness of grain cannot succeed once the condition has been weakened or discarded (see, e.g., Brewer 2005; Chuard 2006). The aim of this paper is to show that the situation is even more dire for nonconceptualists, for even if the re-identification condition remains in its original form, the argument from fineness of grain still fails to make the case for nonconceptualism. This paper argues, in other words, that the re-identification condition actually serves to undermine the conclusion of the argument it purports to support. 
The paper's central case rests on two claims defended in Section 2: according to the first, if the re-identification condition holds, then some beliefs will represent some properties nonconceptually; and according to the second, if some beliefs represent some properties nonconceptually, the argument from fineness of grain fails to make the case for nonconceptualism in an important sense. It follows that if the re-identification condition holds, the argument from fineness of grain fails to make the case for nonconceptualism.

A point of clarification: the aim of this paper isn't to argue against nonconceptualism but rather to show that the argument from fineness of grain cannot be used to make the case for nonconceptualism even if the re-identification condition remains unmodified. This suggests that nonconceptualists should shift their focus away from arguments relying on the condition entirely and attempt instead to develop and strengthen other arguments for their view. ${ }^{3}$ The paper begins with a background discussion, in Section 1, of the fineness of grain argument and the re-identification condition; it ends, in Section 3, with the consideration and rejection of replies on behalf of the nonconceptualist.

\section{Experience and Re-identification}

\subsection{The Conceptual/Nonconceptual Debate}

The debate between conceptualists and nonconceptualists has been notoriously difficult to navigate, in part because it involves two distinct debates which weren't carefully distinguished until recently (see Heck 2000; Byrne 2003; 2005; Speaks 2005). Though these two debates have the same goal, namely to determine the degree to which experiential states are like belief states, their emphases are quite different. The so-called 'content' debate is concerned, as its name suggests, with contents ${ }^{4}$ : its proponents disagree about whether belief and experiential states have contents of the same kind. Content-conceptualists claim that experience and belief do have contents of the same kind-in other words, the content of an experience is of such a kind that it could be the content of a belief. Content-nonconceptualists, meanwhile, deny that experience and belief have contents of the same kind. Since it is widely assumed that concepts are the sole constituents of belief contents, the debate is often described as pitting those who claim that experiential contents, like belief contents, take concepts (and concepts only) as constituents-i.e., the content-conceptualists-against those who claim that experiential contents, unlike belief-contents, have (at least some) constituents that aren't concepts-i.e., the content-nonconceptualists.

By contrast, the so-called 'state' debate is concerned with the relation between the tokening of a state (belief or experience) and concept-possession. Its participants disagree specifically about whether concept-possession is a necessary condition for the tokening of relevant experiences. Since it is widely assumed, in this debate, that possessing the concept RED (i.e., being able to token a belief with the conceptual constituent RED) is a necessary condition for having a belief 
that a tomato is red, the debate can be described as pitting those who claim that possessing the relevant concepts is a necessary condition for tokening the relevant experience-i.e., state-conceptualists-against those who deny that this is the case-i.e., state-nonconceptualists. ${ }^{5}$

It is important to note that the two debates are not equivalent. The truth of state-nonconceptualism does not entail the truth of content-nonconceptualism. To see this, assume state-nonconceptualism is true; e.g., assume that being able to think a thought with the concept RED is not a necessary condition for tokening an experience of red. A thinker may therefore undergo an experience of red and yet be unable to token a belief whose content includes the concept RED. This fact does not entail the truth of content-nonconceptualism: it does not entail, that is, that the content of an experience of red is of a different kind from the content of belief. That our thinker is unable to token a belief with the concept RED doesn't entail that the content of her experience of red is such that it could not possibly be believed. In fact, the truth of state-nonconceptualism entails nothing at all about how experience represents the property of redness. ${ }^{6,7}$

Perhaps unsurprisingly, most philosophers purport to contribute to the content debate, even when they unwittingly contribute to the state debate. Tye's (2000) fineness of grain argument, for instance, turns out to be an argument for state-conceptualism. Since subjects often have experiences that represent shades of colour, like red $_{17}$, without having stored mental representations of themand since having a stored mental representation of a property such as $\operatorname{red}_{17}$ is required to possess the concept $\mathrm{RED}_{17}$-Tye concludes that experience is nonconceptual. As Byrne (2003) and Speaks (2005) both point out, Tye's argument here and arguments like it show at most that possessing a concept like RED 17 is not a necessary condition for experiencing the property it picks out, i.e., $\operatorname{red}_{17}$. Such an argument, in other words, 'establishes at best the state view' (Byrne 2003: 17). Byrne adds:

For all this argument says, a subject's visual experience might have the content that, say, a certain tomato is red ${ }^{19}$, where the proposition that the tomato is red $^{19}$ is the very same kind of proposition-a Fregean Thought, perhaps-that she can believe. (ibid.)

Despite all this, Tye indeed seems to hold the content view. After all, it is the content view (which Tye explicitly attempts to defend in later work, e.g., Tye 2006) that makes sense of Tye's overarching project and of projects like his which aim to explain the phenomenology of experience in terms of experiential contents. ${ }^{8}$ It is also the content debate-and not the state debate-whose outcome seems to bear on the epistemological question that leads a number of philosophers to the debate: a question about how experiential states can ever justify belief states if their contents are of different kinds ${ }^{9}$ (see, e.g., Brewer 1999; 2005; Dokic and Pacherie 2001; McDowell 1994). As a result, the discussion in this paper will be located within the content debate and its focus will be the version of the argument from fineness of grain that constitutes an argument for contentnonconceptualism. ${ }^{10}$ In the remainder of the paper, the terms 'conceptualism' 
and 'nonconceptualism' should be understood as standing for 'contentconceptualism' and 'content-nonconceptualism'.

\subsection{The Re-identification Condition}

The argument from fineness of grain appeals to a so-called 're-identification condition'-a condition which must be met if a subject is to represent a particular perceptual property conceptually. ${ }^{11}$ Chuard (2006) provides a detailed discussion of the various re-identification conditions deployed in the literature. The focus here will be on a version of the condition that is most likely to ensure that the argument from fineness of grain is valid. That version of the reidentification condition-which I'll call RC — can be stated as follows (this is an extension of Chuard's 2006 formulation $^{12}$ ):

(RC) For any perceptual property $p$ to be represented by a subject $S$ using a concept $\mathrm{C}, \mathrm{S}$ must be able to:

(i) identify some object as having $p$ at some time $t$;

(ii) identify some object as having $p$ at time $t+1$;

(iii) be aware that the property $p$ identified at $t+1$ is the same property $p$ identified at $t$

(iv) re-identify $p$ at $t+1$ as the same property p perceived at $t$ based only on the experience and memory of $p$; and

(v) $t$ and $t+1$ must be separated by an interval during which $S$ has no experience of $p$.

To see the condition at work, imagine that a subject, Lisa, is attending to a canvas sprinkled with drops of green paint and is focusing her attention on a drop which has a particular, determinate colour property, say green $17{ }^{13}$ According to $\mathrm{RC}$, in order for Lisa's experience to represent this property of the paint-drop conceptually, Lisa must first be able to (i) identify the drop as being green $_{17}$ at $t$, and then (ii) identify that drop (or another drop) as being green ${ }_{17}$ at some later time $t+1$. The third condition requires that Lisa realize, when she perceives the drop as being green $n_{17}$ at $t+1$, that this is the very same property she perceived the drop as having earlier, at $t \cdot{ }^{14}$ And, indeed, this is what we typically require for re-identification in ordinary cases: subjects who fail to notice that the property they are now perceiving is the same one they were perceiving earlier are not usually said to have re-identified it. In other words, for Lisa to meet the Re-identification Condition, she must (iii) be aware that the two properties she attributes to the drops at $t$ and $t+1$ are the same property green $n_{17}$. This isn't enough, however. For, intuitively speaking, it seems that were Lisa to notice, at $t$, that the drop she's attending to is the third one from the bottom left corner of the canvas, and were she to re-identify the shade at $t+1$ by counting the drops from the bottom left corner, she would fail to meet RC. Indeed, if Lisa must rely on information about the location of the paint drop (or its size, shape, etc.) in 
order to make a judgement about its colour, it seems that she is not actually re-identifying the colour itself. Our intuitions suggest that genuine reidentification of a given perceptual property should be based on a subject's experience of that property at some time $t+1$ together with the perceptual memory of that property which was perceived earlier. In other words, in order for Lisa to truly re-identify green 17 in the way specified by $\mathrm{RC}$, she must rely on her experience of a particular shade and her memory of said shade only.

Finally, were Lisa to look at the green 17 drop and keep her gaze focused on that very drop as the canvas was moved across the studio before re-identifying the shade, she would not necessarily meet RC either. Indeed, she must be able to close her eyes, or look away or in some other way (v) stop experiencing the shade in question in order to meet the condition. ${ }^{15}$ It is worth pointing out, as Kelly (2001) himself does, that the length of the interval between $t$ and $t+1$ can be quite short. Clearly, RC cannot require that one be able to re-identify a property five or ten years after having experienced it. But as long as the experience of the property can be interrupted while subjects retain the capacity to re-identify it, they will have met (v). Note that the fact that RC requires re-identification of a property after an interval of no experience, however short, suggests that it requires the storage in memory (at time $t$ ) of relevant representations and the retrieval at $t+1$ of these representations. Condition (iv) specifies that it is a representation of the relevant property (of the shade green 17 in Lisa's case) that must be stored and retrieved, as opposed to representations of the location (or size, shape, etc.) of an individual object that instantiates that property. ${ }^{16}$

$\mathrm{RC}$, as described above, has struck a number of writers as a rather intuitive condition on perceptual (or observational) concepts, like GREEN and ROUND. Chuard writes that:

most participants in the dispute, we can assume, agree that something like $[\mathrm{RC}]$ governs the possession of normal non-demonstrative concepts like red, car, kangaroo, etc.... At first sight, this is not implausible: we often interpret failures to re-identify red things as evidence that a subject has no concept for redness. (Chuard 2006: 170)

Similarly, Dokic and Pacherie claim that:

it seems plausible to suppose that mastery of an observational concept implies a capacity to identify and re-identify perceptual instances of the concept. This means that, to have a concept of a given colour shade, one must be able to recognize coloured objects over time. (Dokic and Pacherie 2001: 197-8)

And even some conceptualists take there to be such a condition on perceptual concepts. McDowell, in an oft-quoted passage, says:

what ensures that it is a concept, what ensures that thoughts that exploit it have the necessary distance from what would determine it to be true, is that the associated [recognitional] capacity can persist into the future, if only for a short time ... (McDowell 1994: 57) 
Of course, however plausible RC may be as a condition on some general perceptual concepts, like GREEN, or CAR, it is clearly not a plausible condition on all concepts. First, it is clearly not a condition on concepts that pick out imperceptible properties, such as the concept JUSTICE. ${ }^{17}$ Second, RC is not a condition on concepts that pick out perceptual properties deferentially. ${ }^{18}$ After all, it seems clear that it is possible for thinkers to represent objects conceptually without being able to identify-let alone re-identify-them, so long as thinkers defer to experts about the referents of these concepts.

\subsection{The Argument from Fineness of Grain}

The argument from fineness of grain takes the re-identification condition as a premise, along with three other claims, and it can be schematized as follows:

[P1] RC: In order for a subject $S$ to represent a property $p$ conceptually, $S$ must be able to re-identify $p$ as specified in (i)-(v) above.

[P2] Subjects represent fine-grained properties, like green 17 , in experience.

[P3] Subjects do, or could, lack the ability to re-identify these properties as specified in (i) $-(\mathrm{v})$.

[P4] Subjects do not represent fine-grained properties in experience deferentially.

Therefore,

[C1] Subjects do not represent fine-grained properties in experience conceptually.

Therefore,

[C2] Experiential content is unlike the content of belief in that it is at least partly nonconceptual. ${ }^{19}$

Premises [P2], [P3] and [P4] are supposed to be fairly uncontroversial. Interestingly, [P3] can be understood as making either of two claims. The first is an empirical claim, to the effect that human subjects are quite bad at re-identifying fine-grained properties (see, e.g., Raffman 1995). Some of the empirical evidence supporting such a claim is anecdotal, drawing from familiar scenarios (not unlike the one above) involving rows of paint chips in hardware stores. Most subjects are, indeed, unable to re-identify, based on current experience and memory of its shade alone, a colour they'd picked out as a good candidate for a bedroom wall just seconds earlier. But arguments from fineness of grain need not depend on the truth of these empirical claims and [P3] need not be interpreted as such. Indeed, some arguments from fineness of grain (including Kelly's (2001) argument) appeal primarily to the fact that it is (naturally) possible for a human subject's experience to represent a property she couldn't 
re-identify. ${ }^{20}$ Given that re-identification depends crucially on memory, all that is needed is the (natural) possibility that a thinker have a memory bad enough that she be unable to re-identify some fine-grained properties her experience represents. This is all the argument from fineness of grain requires, for it will follow, then, that human experience is a kind of state which, unlike belief, can have constituents that aren't concepts.

[P4], which claims that experience does not represent properties deferentially, is not usually made explicit in statements of the argument, possibly because it seems so obviously true as to be barely worth stating. Indeed it seems clearly true that we could not-in experience-defer to experts about what we experience. Still, for the purposes of this paper, it is worth highlighting the fact that RC-in its 'original' form-entails that someone who cannot re-identify a property must represent it nonconceptually only if we can rule out other ways of conceptually representing the property in question.

\subsection{Fineness of Grain and Demonstratives}

Conceptualists are fond of blocking arguments from fineness of grain by appealing to demonstrative concepts. The move can be construed as a stateconceptualist move against state-nonconceptualism, motivated by the observation that even if experience does indeed represent fine-grained properties for which subjects possess no general, context-independent concepts, still the subjects of experience may possess context-dependent, demonstrative concepts of these fine-grained properties. The problem with the argument from fineness of grain (for state-nonconceptualism) therefore seems to be that it takes 'an unduly restrictive view of concepts as necessarily corresponding to entirely contextindependent classifications of things' (Dokic and Pacherie 2001), forgetting meanwhile the existence of context-dependent demonstrative concepts. ${ }^{21}$ Stateconceptualists conclude that fineness of grain arguments fail to establish the falsity of their view: these arguments fail to show that the possession of some concept (context-independent or not) is not in fact a necessary condition for tokening an experience representing the concept's fine-grained referent.

Of course, the focus of this paper is on the content-nonconceptualist argument from fineness of grain, and content-conceptualists too may want to appeal to demonstrative concepts to diffuse that version of the argument. Indeed a content-conceptualist may argue that it seems possible for fine-grained properties to be represented by a subject $S$ conceptually without the subject either meeting RC or tokening a deferential concept, if $S$ represents these properties demonstratively. ${ }^{22}$ Conceptualists may think that the argument for contentnonconceptualism also takes a restrictive view of concepts, assuming that concepts either must meet RC or must be deferential. If, however, a subject can represent fine-grained properties using demonstrative concepts without meeting $R C$, the conclusions of the argument from fineness of grain stated above simply do not follow from its premises [P1]-[P4]. 
Interestingly, of course, the goal of Kelly's (2001) paper is precisely to argue that $\mathrm{RC}$ is a condition on perceptual demonstrative concepts. ${ }^{23}$ The fact that we can use general concepts deferentially leads Kelly to urge caution when applying the condition to general perceptual concepts, however plausible such an application may seem. He writes:

if it is possible to possess a general concept in virtue of one's capacity to defer to an expert user of terms that express that concept, then it will be possible to possess the concept without being able to satisfy the re-identification condition. (Kelly 2001: 407)

But, Kelly adds, 'this consideration isn't relevant in the case of demonstrative concepts' (ibid.). He concludes that RC is a condition on perceptual demonstrative concepts which entails, it would seem, that the argument from fineness of grain is valid after all. For if RC holds as a condition on perceptual demonstratives, then the conceptualist is wrong when she argues that subjects who don't meet RC could represent fine-grained properties in experience using demonstrative concepts. Experience must therefore represent fine-grained properties nonconceptually. ${ }^{24}$

\section{Belief and Re-identification}

Critics of the argument from fineness of grain usually deny that $R C$ is a condition on demonstrative concepts. These critics claim that RC requires too much, and that it is possible for subjects to represent properties using demonstrative concepts even if they don't meet the condition. Brewer (2005) suggests, for instance, that requiring an interval of no experience is not needed: if a thinker can track a fine-grained property as environmental conditions change-as Lisa would be able to do if she kept her attention focused on the relevant drop while the canvas was moved-then the thinker should count as representing the property using a demonstrative concept. ${ }^{25}$ Chuard (2006) also argues that RC as originally formulated simply cannot be a condition on demonstrative concepts. This section of the paper attempts to show that even if we grant that $\mathrm{RC}$ is in fact a condition on demonstrative concepts, the argument from fineness of grain still fails to make the case for nonconceptualism. The argument proceeds in two steps. According to the first, if RC holds, some belief-contents will have nonconceptual constituents (Section 2.1); according to the second, if some beliefcontents have nonconceptual constituents, the argument from fineness of grain fails to make the case for nonconceptualism (Section 2.2).

\subsection{Belief and Fineness of Grain}

We begin by considering what RC, as originally formulated, entails about beliefs that represent fine-grained properties. Imagine, then, that our subject Lisa is 
attending to the shade of the green 17 paint-drop. As we did earlier, let us stipulate that Lisa does not meet RC. According to the nonconceptualist, this entails that Lisa's experience isn't representing green 17 using a demonstrative (or any) concept. Now imagine that while attending to green 17 , Lisa comes to utter the following English sentence:

(S1) This is the perfect shade for my poster.

The belief that (S1) expresses, in this case, represents a fine-grained property $\left(\right.$ green $\left._{17}\right)$. However, assuming that $\mathrm{RC}$ is a condition on demonstrative concepts will entail that the belief expressed by Lisa with (S1) cannot represent green 17 using a demonstrative concept. Indeed we stipulated that Lisa does not meet $\mathrm{RC}$, and it is this very fact that enables the nonconceptualist to argue that her experience doesn't represent green ${ }_{17}$ using a demonstrative concept. If RC holds, then it follows not only that Lisa's experience cannot represent green ${ }_{17}$ using a demonstrative concept, but that the belief she expresses with the demonstrative sentence (S1) does not represent green ${ }_{17}$ using a demonstrative concept either. The exact reasoning which led the nonconceptualist to conclude that Lisa's experience does not represent green ${ }_{17}$, leads to the conclusion that Lisa's belief cannot represent green ${ }_{17}$ using a demonstrative concept.

Moreover, since we are assuming that RC holds as originally formulated, we are assuming that it is a condition on perceptual demonstrative concepts and on non-deferential perceptual concepts, such as GREEN or ROUND. This means that since Lisa doesn't meet $\mathrm{RC}$, her belief cannot represent green ${ }_{17}$ using a perceptual demonstrative, or a non-deferential perceptual concept. And though it isn't absurd to suppose that Lisa represents green $_{17}$ deferentially when she tokens the belief she expresses with (S1), it does seem highly implausible that this would be the case. For the constituent of the belief-content corresponding to Lisa's demonstrative expression 'this' does not pick out green 17 based on her capacity to defer to experts about colour shades. Were all color experts to vanish, or had they never existed, Lisa could still manage to refer to that very shade of green-for she picks it out based on her capacity to focus her attention on the relevant property and demonstrate it.

What, then, are we to say about the belief Lisa expresses with (S1)? It would seem that Lisa's belief simply cannot be representing the fine-grained shade she demonstrates using 1) a deferential concept (she's not relying on experts), 2) a non-deferential perceptual concept (RC isn't met) or 3) a perceptual demonstrative concept (RC isn't met). Reasoning as the nonconceptualist did in the argument from fineness of grain, we should conclude that Lisa's belief must represent the shade in question nonconceptually. In other words, if RC holds, then some belief-contents will have constituents that are not concepts.

Notice that to claim that belief-contents may have nonconceptual constituents isn't necessarily unreasonable. It does go against the general assumption in the 'content' debate that concepts, and concepts only, are the constituents of belief. However it isn't clear what motivates the claim that concepts are the only possible constituents of belief. After all, regardless of one's ontology, concepts 
will turn out to be 'objects' (mental representations or abstract constituents of propositions) of a certain kind, where the kind in question remains to be delineated. ${ }^{26}$ It is possible, of course, to delineate the relevant kind in such a way as to guarantee that they are the only possible constituents of belief-contents. After all, it is possible to simply assert that any constituent of belief is thereby a concept regardless of what other features it may have. This leaves open the possibility that some of these concepts could be the constituents of experiential contents, even as it rules out the possibility that belief-contents could have nonconceptual constituents. But such a characterization is quite empty, since it fails to identify any interesting, or salient, features of concepts as a kind. It is no wonder, then, that concepts are never actually characterized this way. Instead concepts are claimed to be objects with certain sorts of salient features, and this leaves open the possibility that some constituents of belief-contents may not have the requisite features. Of course, $\mathrm{RC}$ is just such a characterization of concepts. ${ }^{27}$ It shouldn't be especially surprising, therefore, that if $\mathrm{RC}$ is in fact a condition on concepts, then some constituents of belief-contents may not be concepts. According to $\mathrm{RC}$, concepts are objects which meet (i)-(v) above, and though these are indeed features that many constituents of belief-contents will possess, it is by no means necessary that every constituent of belief-contents must meet RC.

Now, as a condition on non-deferential perceptual and demonstrative concepts, RC is a condition on these concepts ('objects') generally, regardless of whether they happen to be constituents of belief- or experiential contents. For a subject to represent a property using a (nondeferential perceptual or demonstrative) concept, whether in experience or in belief (or really in any other state) the constituents of her experiential or belief-content must possess the relevant features. Conversely, a subject whose representational constituents lack the relevant features will not represent the relevant properties using a concept whether in the content of experience or in that belief. Those who endorse RC in its original form, as proponents of the argument from fineness of grain seem to do, should be willing to accept that some of the constituents of belief-contents may not technically be concepts. And this is precisely what nonconceptualists would have to say about beliefs expressed by sentences like (S1): Lisa, in tokening these beliefs, is representing the fine-grained property green $_{17}$ nonconceptually.

One last observation: this may cohere nicely with recent accounts of demonstrative thoughts-for instance, Levine (2010)—according to which the key demonstrative constituents of these thoughts are pointers. ${ }^{28}$ The role of these pointers, according to Levine, is to select a bit of another mental representation (say a visual perceptual one) and to use it to represent the world. On such accounts, when one utters a sentence like (S1), the demonstrative expression expresses a pointer, a mental constituent which directs attention to the visual representation of the green shade and, using that visual representation, succeeds in picking out the shade represented visually. Most importantly, since demonstrative constituents of beliefs expressed by sentences like (S1) are thought to be pointers whose content will change depending on the direction of attention, they 
are unlikely to be the sorts of things that can be stored in memory. In other words, pointers may not meet RC and they may therefore be, in some sense, nonconceptual constituents of belief. In any case, it looks as though RC, in its original form, entails that some beliefs will represent some fine-grained properties nonconceptually.

\subsection{Making the Case for Nonconceptualism}

Though I just argued, in the preceding section, that there is nothing inconsistent about claiming that some belief-contents have some nonconceptual constituents, this fact does ultimately undermine the case for nonconceptualism. Indeed, the 'content' debate between conceptualists and nonconceptualists as described earlier is a debate about whether experience and belief have the same kind of contents. This entails that for any argument to truly be an argument for content-nonconceptualism, it must show not only that experience at least sometimes represents the world using constituents that aren't concepts but also that belief does not. It is no wonder, then, that proponents in the content debate generally assume that belief-contents take concepts and concepts only as constituents-for this assumption ensures that if some of the constituents of experiential contents are not concepts, then experience will indeed be unlike belief in the relevant respect. However, as the previous section suggests, endorsing $\mathrm{RC}$ in its original form undermines the 'content' debate's general assumption about belief, because if RC holds, some constituents of belief-contents may not be concepts. The fact that some constituents of experience are not concepts now fails to entail that belief- and experiential contents have constituents of different kinds. Indeed, if $\mathrm{RC}$ holds in its original form, then the argument from fineness of grain's first conclusion [C1]—according to which subjects do not represent fine-grained properties in experience using concepts-does not entail [C2]-that experience is unlike belief in that it is at least partly nonconceptual. In other words, though RC as originally stated plays a crucial role in getting the nonconceptualist to show that experience represents some properties nonconceptually, it simultaneously prevents the nonconceptualist from making the case that experience is unlike belief in this respect.

Nonconceptualists may suggest, in response, that RC should be slightly modified to avoid this conclusion-as long as it is modified in the right way. ${ }^{29}$ They may insist, for instance, that it is possible for a subject to meet RC-to represent a fine-grained property conceptually-so long as she is able to re-identify the relevant property based on her perceptual experience and memory of the shade together with any other information she might have, such as information about the location of objects. If $\mathrm{RC}$ requires re-identification of this weaker kind, then nonconceptualists can deny that the content of the belief Lisa expresses with (S1) must have a constituent that is not a concept, since Lisa now meets RC. Unfortunately, no such move can succeed, for two reasons. First, if $\mathrm{RC}$ is modified so as to ensure that Lisa meets it, the nonconceptualist will indeed be able to deny that she must represent green $_{17}$ nonconceptually in 
thought, but it will also entail that Lisa's experience could represent green 17 conceptually. Second, after RC is modified, it is possible to re-describe Lisa in a way that guarantees that she fails to meet it. Lisa's memory only need be bad enough, and she will fail to re-identify a particular shade based on the modified criteria. In such a re-described case, the modified RC will entail Lisa could not

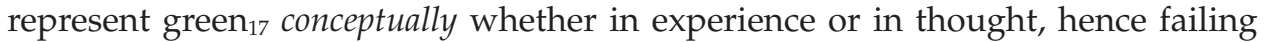
to entail that experience and thought have contents of different kinds. This highlights, once more, a crucial feature of $\mathrm{RC}$, namely the fact that it is a condition on concepts generally-regardless of whether they figure in experiential or in belief-contents. This suggests that nonconceptualists face a dilemma. Either $\mathrm{RC}$ is characterized in such a way that it entails that experience represents fine-grained properties nonconceptually, in which case it will also entail that belief represents some fine-grained properties nonconceptually; or RC is characterized so as to ensure that subjects who represent fine-grained properties in thought meet RC; i.e., that they represent said properties conceptually. Either way, however, we have no reason to conclude that the contents of experience and belief are different kinds of contents; i.e., RC fails to support nonconceptualism.

\section{Objections and Replies}

The argument just presented depends on two crucial claims which may rightfully be called into question by proponents of the argument from fineness of grain. The first concerns the very structure of the debate between conceptualists and nonconceptualists. Indeed, I have assumed that making the case for nonconceptualism requires making the case that experience and belief have contents of different kinds. A nonconceptualist may object that I have mischaracterized the debate. Second, I have assumed that perceptual properties can be represented conceptually in three ways: either using a non-deferential perceptual concept, or using a deferential concept, or using a perceptual demonstrative. One may argue, however, that I have failed to consider the possibility that perceptual properties could be represented conceptually using complex descriptions, such as, e.g., THE SHADE I'M LOOKING AT. I end the paper by considering these two objections and showing why they fail to provide a compelling defence of the nonconceptualist's argument from fineness of grain.

\subsection{The Conceptual/Nonconceptual Debate}

As mentioned in Section 1, the paper assumes that the debate between conceptualists and nonconceptualists is essentially a debate about the content of experience and belief. However, the paper further assumes that the goal of the content debate is to make a comparative claim concerning these contents, with the nonconceptualist claiming that a) experiential and belief-contents are contents of different kinds, and the conceptualist claiming that $\mathrm{a}^{*}$ ) experiential and 
belief-contents are of the same kind. Unfortunately, it seems possible to grant that the conceptual/nonconceptual debate is essentially a debate about content while denying the centrality of these comparative claims. The nonconceptualist may primarily hope to show that $b$ ) some of the constituents of experience are not concepts, while the conceptualist may primarily aim to argue that $b^{*}$ ) all the constituents of experience are concepts. It is true that these claims about experiential contents will entail further comparative claims when considered in tandem with additional claims about the constituents of belief-contents. But why assume, as this paper has, that the main goal of the debate is to settle the truth of the comparative claims a) and $a^{*}$ ) and not to settle the truth of the claims about experience $b$ ) and $\left.b^{*}\right) ?^{30}$

The point can be put into sharper focus if we acknowledge the fact that some nonconceptualists may not be very interested in establishing the truth of the comparative claim which I maintain their argument from fineness of grain aims to support. Such a nonconceptualist may be perfectly happy to believe instead that $\mathrm{a}^{*}$ ) experiential and belief-contents are of the same kind, or to remain entirely uncommitted when it comes to the truth of comparative claims like a) and $a^{*}$ ). What makes her a nonconceptualist nonetheless is the sole fact that she believes that b) some of the constituents of experience are not concepts. Such a nonconceptualist does not, at this juncture, have any reason to think that the argument from fineness of grain and its re-identification condition have failed her. For all I have argued here, endorsing the re-identification condition prevents those nonconceptualists who hope to establish the truth of the claim that experiential and belief-contents are contents of different kinds from reaching their conclusion. It does nothing, however, to undermine a more modest nonconceptualist whose only nonconceptualist goal is to argue that b) some of the constituents of experiential contents are not concepts.

The point is well taken. The argument in this paper does not entail that the argument from fineness of grain undermines the 'modest' nonconceptualist. However, it seems that most nonconceptualists are not in fact so modest. Most nonconceptualists are, whether they realize it or not, interested in defending the truth of a) that experiential and belief-contents are contents of different kinds. Most nonconceptualists, then, will find that endorsing the re-identification condition will prevent them from using the argument from fineness of grain to make their case. Indeed, as I'll argue now, a review of some of the most prominent nonconceptualist arguments suggests that nonconceptualists are motivated by the existence of contrasts between belief and experience which in turn primarily support the comparative conclusion that experiential and beliefcontents are contents of different kinds. This comparative claim will of course have implications about the constituents of experiential contents given further assumptions about the nature of belief-contents. Still, given the arguments they provide, it seems that it is the relation between experiential and belief-contents which concerns nonconceptualists the most.

Consider, first, the various arguments for nonconceptualism that emphasize features of experience that are not features of belief. These arguments (which 
include the argument from fineness of grain) emphasize quite explicitly differences between belief and experiential states. For instance, they highlight the fact that experience, unlike belief, can represent contradictory or impossible states of affairs (see, e.g., Crane 1988), or that experiential content, unlike belief-content, is rich, or analog, or fine-grained, or situation-dependent (see, e.g., Dretske 1981; Tye 2006; Kelly 2001; Siegel 2011), or that it has a distinctive phenomenology, namely a phenomenology that is unlike that of belief (see, e.g., Peacocke 2001; Tye 1995; 2000). The fact that these arguments centrally draw a contrast between experience and belief makes it unlikely that the (content-) nonconceptualists who present and defend these arguments have no interest in establishing a contrastive claim concerning the contents of the relevant states.

It is possible, however, for a more modest nonconceptualist to ignore the contrastive claims that usually motivate arguments for nonconceptualism and focus entirely on experience. Such a modest nonconceptualist aims only to argue for the (noncomparative) conclusion that $b$ ) some of the constituents of experiential contents are not concepts, and as far as she's concerned, the argument from fineness of grain discussed in this paper does a fine job of making the case for (modest) nonconceptualism. Indeed, my claims in this paper do not undermine nonconceptualism so (modestly) construed. The modest nonconceptualist ought to notice, however, that endorsing $\mathrm{RC}$ as part of an argument from fineness of grain commits her to endorsing further claims about the constituents of belief-contents. That is because the very reasoning (using RC) with which the modest nonconceptualist reaches her modest conclusion also supports the claim that belief-contents are partly nonconceptual. Whether or not she cares about belief contents at all, a modest nonconceptualist is nonetheless committed to a substantial claim about them, which in turn will have implications for the truth of comparative claims.

Standard nonconceptualist arguments therefore suggest that nonconceputalists are for the most part concerned with questions about the nature of both experiential and belief-contents and whether they are contents of the same kind. This means that nonconceptualists who use RC should indeed worry about its implication for the constituents of belief. If RC entails not merely that experiential contents are partly nonconceptual but that belief-contents are partly nonconceptual as well, RC fails to support the case for nonconceptualism in the comparative sense. Modest nonconceptualists can use RC to support nonconceptualism as they construe it, but their commitment to the truth of RC commits them to the truth of unexpected claims about belief-contents-that they are partly nonconceptualand about how they do not differ from experiential contents-belief-contents are partly nonconceptual in just the way that experiential contents are.

\subsection{Demonstratives vs. Definite Descriptions}

The case made here assumes-explicitly so, see Section 2.3 - that there are three ways for a subject to represent a fine-grained perceptual property conceptually: 
either she will do so using a general perceptual non-deferential concept, or using a deferential concept, or using a perceptual demonstrative concept. As mentioned several times, $\mathrm{RC}$ in its original form is a condition on both general non-deferential perceptual concepts and on perceptual demonstrative concepts, though it's not a condition on deferential perceptual concepts. But a nonconceptualist may claim that a fourth possibility has been ignored: that a subject could represent a fine-grained perceptual property using a definite description. Lisa could represent green 17 as 'the artist's least favourite shade'; or as 'the shade I singled out the first time I looked at the canvas', and so forth. Consider, then, a case in which Lisa while attending to green ${ }_{17}$ utters the demonstrative sentence:

(S1) This is the perfect shade for my poster.

Nonconceptualists can claim that the belief expressed by (S1) is not a genuine demonstrative belief but is rather a thought whose first constituent is a 'covert' definite description, such as 'the shade I am attending to'. Descriptions like these, it would seem, can be wholly conceptual, and they can be used by subjects to pick out fine-grained properties that they may not be able to re-identify. Nonconceptualists are now in a position to deny what I claimed was true in Section 2.1: they can deny that endorsing RC will entail that some constituents of beliefs will not be concepts. Importantly, they can simultaneously deny that fine-grained shades are represented conceptually in the way they are represented in thought. Indeed, it seems quite unlikely for green 17 to be represented in Lisa's experience by a description like 'the shade I am attending to now'. The definite description makes reference to what is being attended to, and it is unlikely that the concept of ATTENTION could itself be a constituent of the content of experience. The argument from fineness of grain can now go through. Green 17 is represented in Lisa's experience nonconceptually but it is represented in her belief by a complex (conceptual) description. Experience does have some constituents that are of a different kind from the constituents of belief after all.

This nonconceptualist rejoinder is problematic for at least two reasons. First, nonconceptualists themselves believe that it is unlikely for a subject's experience to represent fine-grained properties by deploying the concept ATTENTION (or any other related concept). This is because it seems possible, nonconceptualists argue, for a subject's experience to represent, e.g., green ${ }_{17}$ without possessing the general concepts involved in this sort of description, such as the concept ATTENTION or SHADE (see for instance Peacocke 2001). But if we assume nonconceptualists are right here, what might they say about such a subject were she to think about a particular, fine-grained shade represented in her experience? How is that fine-grained shade represented in the subject's belief that it's pretty, say $?^{31}$ The fine-grained properties, in such a case, cannot be represented using a description such as 'the shade I am attending to'-since the subject does not possess that concept-and these properties cannot be represented by perceptual demonstrative concepts or perceptual non-deferential concepts-for reasons discussed earlier in the paper. This appears to leave only one possibility: the 
constituent of her belief that represents the fine-grained shade is not a concept. ${ }^{32}$ Belief-contents are partly nonconceptual.

But there is another reason to be deeply sceptical of an appeal to hidden descriptions. The plausibility of such an appeal depends on the plausibility of the claim that sentences like (S1), uttered while attention is being directed at a particular shade, express beliefs that are devoid of any demonstrative constituents. $^{33}$ There is nothing inherently wrong with claiming that sentences of a natural language that share a similar surface structure may in fact express beliefs with different constituents and internal structures. However, positing differing internal structure ought to be done for good explanatory reason. Imagine, for instance, that Lisa utters sentence (S1) a few hours after having left the painting studio, while thinking back to the shade.

(S1) This is the perfect shade for my poster.

Lisa, both while attending to the shade and afterwards, utters the exact same sentence, however, we have reason to think that the beliefs expressed by the two sentences are not the same. Indeed, we have reason to think that Lisa's demonstrative expression, uttered outside the studio, may not express the demonstrative concept we assumed her demonstrative expression expressed earlier. This is because, while looking at the paint drop, Lisa's expression refers to the shade by virtue of her attending to the relevant property while experiencing it. But, having left, her thinking back about the shade is not mediated by attention to a currently experienced property. In fact, since by stipulation, Lisa cannot re-identify the shade, she is not remembering the shade and attending to her stored memory representation of it. This gives us reason to think that though the demonstrative expressions may sound the same when uttered, they may in fact express different concepts. In other words, we have reason to think that the demonstrative expression in the second uttering of (S1) may not express a genuine demonstrative concept, but may instead express a description such as THE SHADE I ATTENDED TO EARLIER. Similarly, when Russell argues that sentences of the form 'An A is F', or 'The $\mathrm{A}$ is $\mathrm{F}^{\prime}$ actually have complex hidden logical structures, he does so because positing such structures does quite a bit of explanatory work. Indeed, it enables him to explain how sentences like 'Pegasus does not exist' can be meaningful without committing him to the claim that certain expressions refer to nonexistent objects. And notoriously, it also enables him to explain how certain a posteriori identity claims, such as 'Hesperus is Phosphorus', can be cognitively significant.

By contrast, it is not clear that the nonconceptualist has good explanatory reason for maintaining that sentences like (S1) uttered while attention is being directed at an experienced property nonetheless do not express a genuine demonstrative thought. If the only reason supporting the nonconceptualist's claim is that her claim is compatible with the truth of nonconceptualism, then the argument from fineness of grain has not provided us with any non-questionbegging reason to become nonconceptualists. 
This paper has argued that even if the so-called re-identification condition isn't weakened or modified, still the argument from fineness of grain fails to make the case for nonconceptualism. If RC holds, then some (demonstrative) beliefs will have nonconceptual constituents. And if some beliefs have nonconceptual constituents, then the argument from fineness of grain hasn't succeeded in showing that experience is unlike belief in that it (and not belief) is partly nonconceptual. The upshot for the nonconceptualist is this: either she should reformulate the fineness of grain argument without appealing to RC at all, or she should give up on the fineness of grain argument, despite its prominence, and attempt to support nonconceptualism in some other way. ${ }^{34}$

\author{
Bénédicte Veillet \\ Department of Philosophy \\ University of Michigan-Flint \\ USA \\ veillet.benedicte@gmail.com
}

\title{
NOTES
}

${ }^{1}$ See Dokic and Pacherie 2001; Tye 1995; 2000; 2006; Peacocke 2001, and for discussion Bermúdez and Cahen 2008, Chuard 2006.

2 This is, as mentioned, a rough characterization. For a qualified one, see Section 1.2.

${ }^{3}$ Such as, e.g., arguments from richness-see Tye 2000, Dretske 1995.

4 The terminology is from Heck 2000.

${ }^{5}$ In the paper, capital letters will be used for concepts to emphasize that there need be no commitment, in these discussions, to claims about the ontology of concepts. Whether concepts turn out to be abstract constituents of propositions or mental representations, the arguments in these debates can be deployed.

${ }^{6}$ Despite acknowledging that the debates are logically independent, authors such as Bermúdez (2007) have argued that they are importantly related. Whether or not Bermúdez is right should have no bearing on the central thesis of this paper.

${ }^{7}$ It is also worth noting that it is possible for a content-conceptualist to claim that a concept is a constituent of a subject's experience even if the subject in question does not possess the concept, i.e., cannot token a belief which takes the concept as a constituent. See, e.g., Byrne 2005.

${ }^{8}$ See also, Bermúdez 2007. Such projects further assume that beliefs lack characteristic phenomenology - though it should be noted that it is by no means obviously true that there is no cognitive phenomenology (see Bayne and Montague's (2011) anthology for discussion).

${ }^{9}$ Worries about the debate so construed are discussed in some detail in Section 3.2.

${ }^{10}$ Note that the argument from fineness of grain cannot make the case that the content of experience is wholly nonconceptual. The fact that it is partly nonconceptual, however, is enough to warrant a nonconceptualist conclusion: that experience and belief are states of a different kind.

11 The condition is sometimes stated as a condition on concept possession (including by Kelly 2001, and Dokic and Pacherie 2001). But possessing a concept, on even the most minimalist construal, is to be able to token a belief with that concept as a constituent. Our concern here, however, is whether concepts can be constituents of experience. 
${ }^{12}$ Chuard's explicit statement of this 'strong' RC, only includes conditions (i)-(iii), though he clearly thinks it includes conditions (iv) and (v) as well. See Chuard 2006: 195 (notes 6 and 7).

${ }^{13}$ The relevant perceptual properties are properties of objects that can be representedaccurately or not-by subjects in experience and in thought.

${ }^{14}$ Chuard calls this type of recognition de dicto re-identification and contrasts it with de re re-identification which doesn't require that subjects be aware that the property they've just identified was the same one they identified earlier (2006: 168-9).

${ }^{15}$ Note that requirements (iv) and (v) may be intimately related: it may be to ensure that condition (iv) is met-that subjects can re-identify properties such as shade only based on their experience of that shade and memory-that, as (v) states, an interval of time between $t$ and $t+1$ is required. After all, insisting that there be an interval of time during which the subject $S$ has no experience of the relevant property will make it less likely that $\mathrm{S}$ is re-identifying the shade at $t+1$ merely based on the tracking of its location (and not based on the experience of the property itself). Still, merely requiring an interval of no experience does not guarantee that the subject's re-identification of green 17 at $t+1$ will in fact only be based on her experience of the shade and memory: as described earlier, it is possible for Lisa to memorize the location of the drop, and therefore to re-identify the shade after an interval of no experience. So both conditions (iv) and (v) need to be met, for a subject to really meet RC.

16 The importance of memory storage is made explicit in Dokic and Pacherie 2001 who claim that it makes thinking (i.e., inferences) possible; and by Chuard 2006 who criticizes this feature of RC specifically in his thought-experiments (Chuard 2006: 183-4, 189-90, 192-3).

17 Presumably, RC doesn't apply to concepts that pick out perceptual properties that cannot be, as a matter of principle, re-identified, such as THIS INSTANTENOUS OBJECT. Thanks to an anonymous referee for the European Journal of Philosophy for pointing this out.

${ }^{18} \mathrm{I}$ am merely claiming here that RC is not a plausible condition on deferential concepts—something which Kelly himself notes (2001). Importantly, I am not claiming that all non-deferential concepts therefore must meet RC. It is indeed possible for an expert to have non-deferential concepts of unperceivable properties (like being just, or being God). I come back to deferential concepts in Section 1.3.

${ }_{19}$ Notice that the argument from fineness of grain shows, at most, that experience is partly nonconceptual-as opposed to wholly nonconceptual. Indeed, even if it turns out that fine-grained properties must be represented in experience nonconceptually, it isn't usually argued, in discussion of the argument, that experience represents fine-grained properties only. It remains a possibility, then, that experience could represent coarsegrained properties (like being a tree or being a car) conceptually.

${ }^{20} \mathrm{He}$ writes 'it's possible to imagine, and we may even be capable of, making perceptual discriminations in cases in which we fail to satisfy the criteria on possessing demonstrative concepts for the things discriminated' (2001: 402-3).

${ }^{21}$ Of course, Pacherie and Dokic go on to argue that the demonstrative stateconceptualist move fails.

${ }_{22}$ This is McDowell's (1994) strategy among others (Brewer 2005, etc.)

${ }^{23}$ Though he admits he isn't presenting any 'conclusive arguments' for that conclusion, merely a number of considerations in its favour.

${ }^{24}$ The assumption that there are only three possible ways of representing a finegrained property conceptually can be questioned (see Section 3). 
25 This amounts to eliminating requirements (iv) and (v) from the statement of RC.

${ }^{26}$ I leave aside here the question of whether concepts form a natural kind-Machery 2009 has recently argued that they do not. This is compatible with the claims made in this paper.

${ }^{27}$ I do not mean to suggest that RC is the only plausible characterization of concepts. The aim of this paper, however, is to argue that $\mathrm{RC}$, which plays such a central role in arguments of fineness of grain, does not actually entail the truth of nonconceptualism.

${ }^{28}$ Levine references Pylyshyn 2003, who also uses the pointer analogy in discussing the early visual system.

${ }^{29}$ Clearly, claiming that RC isn't in fact a condition on demonstrative concepts (à la Chuard) isn't an option. Indeed, as mentioned earlier, such a move undermines the argument from fineness of grain by leaving open the possibility that subjects represent fine-grained properties in experience using demonstrative concepts. And remember that the aim of this paper is to argue that even if RC remains a condition on demonstrative concepts (something which critics of the argument usually deny with devastating implications for the nonconceptualist), the argument from fineness of grain still fails to make the case for nonconceptualism.

${ }^{30}$ Thanks to an anonymous referee for the European Journal of Philosophy for pressing me on this point.

${ }^{31}$ Presumably, such a subject could not think that this is the perfect shade for my poster, since she cannot think with the concept SHADE. She would presumably then not utter (S1) either, but instead may utter: (S2) This is pretty.

${ }^{32}$ I do assume here that the only remaining possibility is that the relevant fine-grained property would be represented by something that is not a concept. Now it is actually possible for someone to insist that, since the subject lacks a concept to pick out the fine-grained property, the subject simply cannot think about the property. (Thanks to an anonymous referee for the European Journal of Philosophy for pointing this out). When this subject utters the demonstrative sentence (S2) This is pretty (see note 31), she simply fails to express a thought that is about the determinate shade of green. However, it is not clear what non-question-begging reasons we would have for thinking that the subject fails to think about the relevant shade.

33 The definite description will contain some indexicals, of course, as in the shade $I$ am perceiving now.'

${ }^{34}$ Many thanks to Peter Carruthers, Georges Rey, Ryan Millsap, and an anonymous referee for the European Journal of Philosophy for their insightful suggestions. Thanks also to the audience of the APA session during which I presented an earlier version of this paper and especially to Philippe Chuard for being a most helpful commentator.

\section{REFERENCES}

Bayne, T. and Montague, M. (2011), Cognitive Phenomenology. Oxford: Oxford University Press.

Bermúdez, J. L. (2007), 'What is at Stake in the Debate about Nonconceptual Content?' Philosophical Perspectives, 21: 55-72.

Bermúdez, J. and Cahen, A. (2008), 'Nonconceptual Mental Content', in E. Zalta (ed.) The Stanford Encyclopedia of Philosophy. Online at: http://plato.stanford.edu/archives/ win2008/entries/content-nonconceptual/

Brewer, B. (1999), Perception and Reason. Oxford: Oxford University Press. 
(2005), 'Perceptual Experience has Conceptual Content', in E. Sosa and M. Steup (eds) Contemporary Debates in Epistemology. Oxford: Blackwell Publishing.

Byrne, A. (2003), 'Consciousness and Nonconceptual Content', Philosophical Studies, 113: 261-74.

- (2005), 'Perception and Conceptual Content', in E. Sosa and M. Steup (eds) Contemporary Debates in Epistemology. Oxford: Blackwell Publishing.

Chuard, P. (2006), 'Demonstrative Concepts without Reidentification', Philosophical Studies, 130: 153-201.

Crane, T. (1988), 'The waterfall illusion', Analysis, 48: 142-47.

Dokic, J. and Pacherie, E. (2001), 'Shades and Concepts', Analysis, 61: 193-201.

Dretske, F. (1995), Naturalizing the Mind. Cambridge, MA: MIT Press.

- (1981), Knowledge and the Flow of Information. Cambridge, MA: MIT Press.

Heck, R. G. (2000), 'Nonconceptual Content and the Space of Reasons', Philosophical Review, 109: 483-523.

Kelly, S. (2001), 'Demonstrative Concepts and Experience', Philosophical Review, 110: 397-420.

Levine, J. (2010), 'Demonstrative Thought', Mind and Language, 25: 169-95.

Machery, E. (2009), Doing Without Concepts. Oxford: Oxford University Press.

McDowell, J. (1994), Mind and World. Cambridge: Harvard University Press.

Peacocke, C. (2001), 'Does Perception have a Nonconceptual Content?' Journal of Philosophy, 98: 239-64.

Pylyshyn, Z. (2003), Seeing and Visualizing. Cambridge, MA: MIT Press.

Raffman, D. (1995), 'On the Persistence of Phenomenology', in T. Metzinger (ed.) Conscious Experience. Paderborn: Ferdinand Schöningh.

Siegel, S. (2006), 'Which Properties are Represented in Perception?' in T. Gendler Szabo and J. Hawthorne (eds) Perceptual Experience. Oxford: Oxford University Press.

- (2011), 'The Contents of Perception', in E. Zalta (ed.) The Stanford Encyclopedia of Philosophy (Winter2011 Edition). Online at: http://plato.stanford.edu/archives/ win2011/entries/perception-contents/

Speaks, J. (2005), 'Is There a Problem about Nonconceptual Content?' Philosophical Review, 114: 359-98.

Tye, M. (1995), Ten Problems of Consciousness: A Representational Theory of the Phenomenal Mind. Cambridge, MA: MIT Press.

(2000), Consciousness, Color and Content. Cambridge, MA: MIT Press.

(2006), 'Nonconceptual Content, Richness, and Fineness of Grain', in T. Gendler Szabo and J. Hawthorne (eds) Perceptual Experience. Oxford: Oxford University Press. 